\title{
Honoring the spirit of research within: The yoga and more (CAM) research interest group
}

\author{
J udith M Fouladbakhsh, Susan Szczesny, Kathleen Kowalewski, Darlene Blair \\ College of Nursing, Wayne State University, Detroit, Michigan, United States
}

Correspondence: Judith M Fouladbakhsh. Address: 5557 Cass Avenue, Detroit, MI 48202. Email: Dr.J@wayne.edu.

Received: May 30, 2012

DOI : $10.5430 /$ jnep.v3n2p132

\section{Abstract}

This article explores the means and methods by which nurses can become actively involved in the search for answers through the research process. It presents one unique example that illustrates research involvement for nurses and other healthcare providers at all levels of practice with a focus on complementary and alternative medicine (CAM). The establishment of the Yoga and More (CAM) Research Interest Group (RIG) at a research-intensive college of nursing, and the members' involvement in a funded pilot study on yoga for lung cancer survivors is presented. The starting point included establishing the research questions and potential solutions, and reinforces the belief that research promotes improved care, better patient outcomes, enhanced quality of life, and increased satisfaction among care providers. In addition, we provide an example of how active involvement in the research process with supportive mentorship promotes "learning-in-action" and stimulates continued interest and growth in the research process. The development and evolution of this innovative research initiative is discussed from a theoretical, methodological and personal perspective with implications for nurses seeking to become involved in the research process.

\section{Key words}

Research, Mentorship, CAM, Nurses

\section{I ntroduction}

As nursing professionals, we all have questions that arise from time to time in our heads, and indeed in our hearts, on how to improve the health care of our patients and their families. For example, we may wonder why that 40 year old woman continues to suffer unremitting chronic pain despite our best endeavors, or why those adolescents at the neurology clinic experience increasing episodes of debilitating headaches that significantly impair their quality of life. The questions we have regarding our nursing care, whether occurring during our practice hours, shortly before sleep, or in our dreams, seem to go on and on, making us wonder how we can ever find the answers.

For the majority of registered nurses (RNs), one answer seems obvious: leave it to the researchers. For others, however, the spirit to become involved in finding the clues, and perhaps the answers, to improved health care is much stronger. These nurses may want to join a research group, but what often remains unclear is how they can become involved in the research process. Compounding that uncertainty is the fear and doubt about one's own abilities related to research. Some questions a nurse may reflect on include: "How could I possibly be involved in research without the necessary credentials, and of 
course, the essential education?" and "Who really cares about my questions from the bedside?” The nurse may also wonder how to find the research partners to begin the work of seeking solutions to improve care. Although many questions remain, the desire to find answers may triumph, if the right path is illuminated.

This article explores the means and methods by which nurses can become actively involved in the search for answers through the research process. It presents one unique example that illustrates research involvement for nurses and other healthcare providers at all levels of practice. The journey begins with the establishment of a Research Interest Group (RIG) focused on complementary and alternative medicine (CAM) therapies, such as yoga, for symptom management and health promotion. The initial research study undertaken by this RIG focused on yoga for mood, sleep, and quality of life of non-small cell lung cancer survivors; the following discussion highlights the RIG initiation, development and evolution. The starting point included establishing the research questions and potential solutions, and reinforces the belief that research promotes improved care, better patient outcomes, enhanced quality of life, and increased satisfaction among care providers. In addition, we provide an example of how active involvement in the research process with supportive mentorship promotes "learning-in-action" and stimulates continued interest and growth in the research process. The development and implementation of this innovative research initiative that focused on complementary, alternative and integrative care at a research-intensive college of nursing is discussed from a theoretical, methodological and personal perspective. An overview of the research initiative, impetus and development of the Yoga \& More (CAM) Research Interest Group (RIG) and factors influencing research outcomes are presented.

\section{Overview of research initiative}

The issue of "how" to get nurses involved in research needs to be addressed. All baccalaureate and higher prepared nurses have had research in their education. The way in which the research process is presented by faculty will impact the individual's perceptions, beliefs and feelings, and ultimately influence plans for involvement, in a positive or negative way. One author has less than fond memories of her own undergraduate experience in research. It involved running around the Intensive Care units of a major teaching hospital, contact agar plates in hand, culturing bed sheets. Despite the findings being non-supportive of the hospital's current bed linen exchange procedures, her study was widely ridiculed and ignored. Today's nurse clinician might be older than in the past, and may feel that "what worked then, works now," negating the need for research or involvement in it.

In contrast, nurse researchers continually experience the pressures of research deadlines, grant writing, funding decisions, and other demands. Excluding practicing nurses and clinicians might make the process easier. Nurses choosing positions in academe, especially instructor positions, must of necessity find a "research home," include research findings in education (classroom and clinical), and still meet the other responsibilities of the job. Research continues to be viewed as labor intensive, time consuming and possibly, anxiety provoking. For the clinical nurse, these challenges are further intensified by their uncertainty of how to become involved and understanding where they fit in the research process.

The need for and importance of research within academic centers of nursing has been well established over the past several decades $^{[1,2]}$, with successes and failures evident among research scholars. The impetus to secure funding for research on symptom management vigorously continues as we seek to ameliorate the increasing burden of chronic illness and improve overall functioning and quality of life for our patients and their families. Despite continuing advances in conventional healthcare treatment, symptom burden remains high, especially among those with cancer and other chronic illnesses ${ }^{[3-14]}$, prompting increasing exploration of complementary and alternative medicine (CAM) therapies for symptom management ${ }^{[3,15-21]}$. As the evidence-base for CAM increases, more treatment options become available with the concurrent establishment of integrative medicine and nursing care models and health care delivery systems across the country and globally. CAM therapies may offer potential benefits as supportive adjuncts to conventional care, and therefore they require further rigorous study. This path will help us to understand outcomes, risks and potential 
interactions with conventional treatments and effects on overall quality of life. Also needed are studies documenting CAM use within nursing and how evidence-based CAM will affect clinical practice models.

To address this need, an interdisciplinary, multi-level research interest group (RIG) was created at a Midwestern college of nursing to explore the effects of CAM therapies, such as yoga, for symptom management among diverse populations. The first study for the RIG focused on yoga for non-small cell lung cancer survivors and is presented in this paper as an example of RIG involvement. Inherent within this process was the active involvement of nurses at all levels of practice, from novices learning about the profession, to nurses working at the bedside, to research experts aiming to address important questions related to patient care and quality of life. The RIG team was also open to others in the health professions, recognizing the importance of an interdisciplinary approach to the research process. The lessons lived and learned are shared here to provide a model of active research involvement and collaboration at all levels of practice.

\subsection{I mpetus for development}

\subsubsection{CAM, symptom burden and nursing practice}

The increased use of CAM by health care consumers and acceptance by providers has created the need for research on CAM therapies and the development of standards of care. Consumers of health care have become increasingly participatory in their care and less accepting of the "doctor is in charge" approach of the past. Nurses are in a unique position to be on the forefront of this new research, which ideally would be interdisciplinary and integrative in nature.

The philosophical premise of many CAM therapies, which have existed for millennia, includes a strong focus on mind-body and spiritual traditions (for example yoga, meditation, tai chi) which correlates closely with the foundation of nursing as established by Nightingale in the 19th century. That time point in our history provided a strong emphasis on caring, comfort and recognition of the holistic nature of human beings. Establishment of the American Holistic Nurses Association in the 20th century further strengthened the importance and critical need for nurses to address the mind-body-spirit of those we care for, especially as significant technological advances occurred which took nurses further from the bedside. CAM therapies, many of which are integral components of global alternative medical systems such as Traditional Chinese Medicine (TCM), Ayurveda, and Native (Traditional) Healing systems, often incorporate this holistic perspective. Use of selected CAM therapies in nursing practice has been ongoing and is usually based upon individual nurse initiative and preparation. Yet understanding how and in what context nurses use these therapies is still unclear. Whereas the move toward integrative nursing practice is in its infancy and still being defined, the philosophical perspective of holistic care has remained a strong force. Research on CAM and integrative nursing is needed to determine and maximize potential benefits, prevent harmful interactions with conventional treatments, and understand the role and scope of nursing. The role of CAM therapies within clinical nursing practice thus requires further illumination.

Whereas, CAM education within schools of nursing is becoming more prevalent and is supported by national credentialing and certifying requirements, the inclusion of CAM within the nursing scope of practice requires further clarification. With the increasing prevalence of CAM use across the United States (as many as $80 \%$ of adults using at least one therapy), and highest use among cancer patients and survivors $(39 \%-43 \%)^{[4,5]}$, it is imperative that nurses understand and assess its use

among patients ${ }^{[22]}$. Understanding what our patients are using and why leads us to the next step: the development of the evidence base for selected therapies that may be included into the provision of nursing care. Once we understand the benefits and risks of therapies within CAM, and as integrative medicine continues to grow, nursing will also develop an integrative nursing model. This model would incorporate evidence-based CAM therapies into the nursing plan of care to manage symptoms, maximize comfort, improve functioning and enhance overall quality of life of our patients

The factors we have discussed above provided the impetus for the development of our CAM research initiative within a college of nursing at a Carnegie Level One research university. The seeds for this initiative were planted over a 2-year 
time period among faculty within the Family, Community and Mental Health area by the first author, who has extensive clinical preparation in CAM, and related CAM research experience.

Prior research examining prevalence of CAM use across the United States among cancer survivors identified the low odds of use of yoga among males with cancer, and the effects of symptoms on yoga practice ${ }^{[5]}$. Clearly evident is the lack of yoga research among male cancer survivors, as the vast majority of studies have focused on women with breast cancer. In addition, there is a dearth of information on CAM use and effects among those with lung cancer, an understudied population with high symptom burden. Thus, it was deemed important to study yoga in a gender-diverse cancer group to ascertain feasibility and effects on mood, sleep, breathing ease and quality of life. Since yoga practice includes a strong focus on the breath, a sample of non-small cell lung cancer survivors was selected for our initial 14-week, one group (yoga intervention only) pilot research study (with follow-up included at 3 and 6 months). Yoga classes were provided in the community using a standardized protocol of viniyoga (hatha yoga) that included yoga poses (asanas), breathing exercises (pranayama) and meditation (dhyana). Outcomes of yoga practice among this pilot group were positive, and support future studies. Plans for a larger scale randomized controlled trial are currently under review at the National Institutes of Health.

\subsubsection{Research misperceptions and beliefs}

An additional and very important factor motivating our research initiative was the initial negative response among nursing colleagues, clinicians as well as fellow researchers. (While this seems contradictory, motivation was increased to dispel misinformation.) These seasoned professionals perceived yoga as much too demanding for the study population, which was also viewed in a negative light. Common stereotyping included the view that lung cancer patients would not be interested in a movement practice (i.e., as a group that does not value health promotion), and/or would be incapable of physical movement (too sick to consider yoga or exercise). Misperceptions about yoga were also evident, with many seeing this as involving intense movement and positioning, demonstrating a lack of awareness of yoga's rich and diverse traditions. Educating colleagues about CAM subsequently became a part of our research initiative. Thus, the seeds were planted over time, awareness was raised, and the Yoga \& More (CAM) Research Interest Group (RIG) was born.

\subsection{Yoga \& More (CAM) research interest group}

\subsubsection{Process of development - framing the Yoga \& More RIG team}

The starting point of this initiative began with education, not only about research methodology, but also about CAM therapies, and more specifically, yoga - what it is and what it is not. Education on CAM was indicated for faculty at multiple levels (researchers, administrators and clinical faculty), as well as college support staff (secretaries, instructional technology staff, etc.) and students. While this sounds extensive, it was deemed as critical by the principal investigator (PI), who has many years of experience with yoga and insight into the power of knowledge and accurate perception. Education was provided via two different pathways: a) dissemination of CAM information via classroom presentations as well as discussions (formal and informal) at faculty meetings; b) scheduling mid-day lunch-time yoga classes for faculty, staff and students. Direct experience with yoga practice provided contact with a highly experienced yoga teacher, promoted visibility of this CAM practice within a traditional nursing school, and allowed for increased understanding of this ancient and complex therapy advocated by Ayurvedic medicine and used worldwide.

Coinciding with the dissemination of CAM information over a 2-year period was proposal preparation to secure research funding to conduct the initial study. Success was achieved by securing small grant financial support from two professional nursing foundations which covered direct study costs but excluded faculty and personnel salaries. The study co-investigator and Director of the College Biophysical Laboratory provided additional support by allowing use of the new lab facilities for analysis of biological specimens, and also training of RIG members in specimen collection.

RIG members were recruited by issuing a call for "research assistants" in several different ways: a) announcements were made at faculty meetings by the lead author/PI; b) flyers announcing the initial study were distributed across the university 
campus and at healthcare agencies; c) information was shared with graduate and undergraduate students and academic advisors at the college of nursing; d) one-on-one conversations (PI and colleagues) took place on a regular basis. Students seeking completion of directed (independent) study credits were referred to the PI, a faculty member of longstanding at the university.

\subsubsection{RIG members}

The team members responded to the call to join the Yoga \& More (CAM) RIG. This call was issued at faculty meetings and extended to graduate students seeking directed study options. Information about the study was also circulated throughout the campus community via email messages to the school of medicine list serve, and at the university and National Cancer Institute-affiliated medical center. The 12-member RIG team included three master's prepared clinical faculty members, three graduate and undergraduate nursing students, two new graduate RNs, a senior medical student interested in pursuing an integrative medicine residency, and an experienced yoga teacher. The RIG was coordinated by the study PI, with support from the two study co-investigators (Assistant Dean and Director of the Biophysical Laboratory, and the study biostatistician). Each member self-selected this RIG and exhibited a high level of commitment to the initial study. Because most members of the Yoga and More (CAM) RIG had not known each other before joining the team, the need to develop into an effective, productive team also was addressed

The RIG members provided the manpower to recruit and enroll study participants, collect data over the 14-week study period and at 2 follow-up time points, and assist with data entry and analysis. Additional resources provided to the team included laboratory training related to biophysiological measurements, and statistical support by senior college of nursing research faculty. Diversity in age, gender, and years of clinical experience among the Yoga \& More (CAM) RIG team encouraged collaboration rather than competitiveness. The team composition also provided an encouraging and supportive environment to spur team members on to continue their educational studies with a focus on nursing research.

Bliss ${ }^{[23]}$ describes a well-functioning research team as a group of people dedicated to a common purpose. Each member joined the Yoga \& More RIG with their own professional and personal goals. Some needed to complete an independent study for graduation credits, others desired to increase their research knowledge and be mentored in publication and presentation skills. All demonstrated a sincere interest in supportive care measures for patients and survivors of lung cancer and the heavy burden of symptoms experienced over the survivorship period. The members were also linked by a desire to increase research skills and knowledge on a clinical topic of personal interest in an open and secure environment.

\subsubsection{RIG Preparation and education}

The RIG team members needed to be educated and updated in several areas including but not limited to: a) CAM therapies and the research protocol; b) research principles and methodology; c) protection of human subjects and the Internal Review Board (IRB) process; and d) data collection, including appropriate measures for biochemical materials. Due to the conflicting schedules and geographic locations of team members, the PI chose to use an internet scheduling tool to determine times for team meetings and trainings. Group-interactive training involved team members who were actively engaged in organized intragroup discussion on training subject content ${ }^{[24]}$. The study protocol included administration of multiple questionnaires, assessment of physical parameters of participants (spirometry and pulse oximetry measurements), and collection of saliva for cortisol analysis. A series of group meetings as well as onsite training facilitated the training of all research team members on the intent and application of the study protocol. Training by a senior level faculty well versed in biochemical specimen collection enhanced the accuracy of the data collection and helped ensure valid study results.

\subsubsection{Experiential learning model}

The call went out to invite professionals from a variety of college and community settings who were interested in participating in CAM research. There are a variety of research capacity and capability enhancing models described in the nursing literature ${ }^{[25]}$. The Experiential Learning Model was a good fit with this team as it requires individual commitment 
rather than hospital or institutional commitment. This was important for this team as all the members were volunteers who contributed to the study in their free time (small funding through professional foundations did not allow for funds to "buy out” faculty work time) despite the need for a pilot feasibility study. The Experiential Learning Model describes a partnership between research experts and research novices that is both collaborative and mentoring ${ }^{[26]}$. The model requires skilled leadership by the team leader/PI and professional respect for novice researchers. This collaboration has been found to contribute to establishing realistic objectives, good communication channels and a supportive learning and research environment for all participants ${ }^{[27]}$.

\subsubsection{Critical role of collaboration}

Working in a large urban university provided a supportive environment to foster collaborative research groups/teams. The college of nursing was charged with increasing research productivity and scholarly activities without increasing costs. The secondary goal was to increase collaboration and mentorship throughout the college and with nurses in clinical practice, thereby promoting knowledge and involvement of nurses at all levels in the research process. This was viewed as a mechanism to strengthen values and attitudes toward research, while alleviating fear, anxiety and a perceived sense of unimportance and unpreparedness for this level of work. The sense of collaboration and perceived valuing of all members' ideas was a strong motivator to remain an active member of the group. The inclusive leadership of the PI as well as that of the Director of the Biophysical Laboratory fostered the development of mutual respect, concern and caring for fellow team members. In addition, direct involvement with the research protocol and contact with study participants enhanced the perception of the importance of the work.

\subsubsection{RIG leadership}

The development of the Yoga \& More (CAM) RIG began to take shape as members volunteered to participate. As with any team, a clear leader had to be identified. Team development began with a senior, doctoral-prepared nurse researcher with a defined area of research. In addition, this leader has strong networks with local, regional, national, and international CAM/integrative oncology research and clinical practice communities. A key attribute for successful team leadership is for the individual to be an active member in a nursing specialty and in interdisciplinary professional organizations ${ }^{[28]}$. The team leader (PI) also needs to possess strong clinical qualifications to encourage team members to join in the proposed research project ${ }^{[28]}$. The roles of the senior nurse researcher included that of experienced teacher, coach, mentor and motivator. This leader's ability to consistently communicate a passion for the research topic and to generate excitement and enthusiasm successfully promoted the development of our team. In addition, recognition of the personal goals of the team members strengthened the collaborative relationships, resulting in increased commitment to the research group.

In this study, "mentoring" involved "teaching” so that team members gained new knowledge and new skills. This was demonstrated by the PI's involvement in a team member-study participant issue. An elderly male participant had shared his lack of Thanksgiving Day plans with a team member, whose initial response was to include him in her own family's celebration. The PI calmly and non-judgmentally explained how this might lead to unnecessary contamination of the study. Another team member, more familiar with the community/area in which the study was conducted, was able to offer the possibility for the participant to attend a Thanksgiving dinner sponsored by and located at a non-study related health care facility specifically for seniors. This strategy resulted in no one on the research team being belittled or criticized and the gain of both research and community knowledge.

The PI maintained clear authority for the study while becoming a mentor and coach for the team. As any coach would, she consistently used effective, nonjudgmental listening and questioning. Clear instructions were given, expectations were made clear at the beginning of the study and at each study session, and appropriate feedback was given and received throughout the course of the study. This feedback was verbal, electronic and/or written. Each session was organized, from assignment of tasks and duties to preparation for subsequent sessions. Possibly from this approach, team members became involved in making sure that subsequent sessions had adequate personnel coverage, without waiting for the PI to ascertain this. Once the study ended, members interested in manuscript development were also identified. 


\subsubsection{RIG support and progress}

Monthly RIG meetings were held to review progress in the research study and identify future research topics. The PI continued to motivate the research team by sharing scholarly activities highlighting the initial findings, such as refereed publications and poster/podium presentations at local, national and international integrative and oncology conferences. Seeing the research process come to life provided a strong impetus to continue the work.

\section{Factors influencing success}

The "myths of research" described by Vickers ${ }^{[29]}$ includes a statement indicating that "anyone can do research." It can be argued that employers, both in academe and health care agencies, perpetuate this myth by including "research" in job duties without evaluating the preparedness and skill of the employee. It is doubtful that any healthcare agency would allow an inexperienced, ill prepared, self-doubting individual to care for their clients. Similarly, any academic institution would most likely not allow an inexperienced, self-doubting individual access to the teaching position in a classroom. Why, then, is research regarded as a "one size fits all," "anyone can do it" endeavor? What are the mechanisms to involve interested nurses and healthcare providers in the research process when the desire does exist? And how does one attain the appropriate experience/skills needed to be involved?

Our research initiative successfully demonstrated that it is possible to involve a multi-layered team of nurses and other healthcare providers when certain criteria are met. Prioritizing the list has proven difficult, but what appears most critical is motivation and commitment to the team and to the goals of the research. Individual motives for joining the Yoga and More (CAM) RIG provided initial impetus; actively participating during one's free time to support successful completion of the study required dedication and a strong sense of group cohesion over the 9-month study period. Providing a supportive environment for "learning-in-action" throughout the research process supported intellectual growth and self-awareness of the team members and provided additional incentive to remain committed. Sharing of study results as data analysis ensued also proved to be a motivating force that kept the team involved.

Anticipated barriers to success included: a) potential lack of willingness to collaborate with others; b) inability to adjust schedules to meet group needs (and cover all study sessions); c) untimely completion of required IRB educational training requirements; and d) protocol violations (e.g., inaccuracies in data collection despite training). The PI remained on site at all study sessions (once per week for 14 weeks and at 2 follow-up time points) to closely monitor compliance and RIG team performance; no barriers were noted and team cohesiveness was evident throughout the study period.

In addition, adopting an inclusive perspective for team membership provided a vehicle for utilization of individual known and hidden skills and talents that became evident as the team evolved. This was further enhanced by the interdisciplinary and multi-generational nature of the RIG, and also by the leadership skills of the PI who successfully motivated, mentored and coached the members toward successful study completion. In this experience, the majority of members expressed an interest in continuing with the RIG and in welcoming new team members for future planned studies.

\section{Conclusions}

In this research "journey," team members originally shared an interest in CAM and welcomed the opportunity for involvement in the initial study on yoga for multiple reasons. Over the course of the study, they went on to increase their knowledge of CAM, develop collaborative skills, and form a cohesive, effective team. Cohen and Bailey ${ }^{[30]}$ define a team as "a collection of individuals who are interdependent in their tasks, share responsibility for outcomes, see themselves and are seen by others as an intact social entity in one or more social systems and who manage their relationships across organizational boundaries." The nature and structure of teams may be taken for granted or overlooked. Individuals may be assigned to a team without any interest in, or knowledge of, the team's goals or any motivation to become an effective team member. The experience described here was that of a collection of individuals evolving into an effective, productive, 
successful team. As a result, the initial study on yoga was completed successfully, and the RIG has gone on to support a larger scale proposal which was very well received at the NIH (resubmission in review). In addition, the insights of the RIG members have led to the development and funding of another pilot study on reflexology for adolescents with recurrent headaches which will begin in fall 2012. The power of a motivated, cohesive and interested group has been evident, leading to new ideas and creative initiatives to enhance patient care.

The roles of research include linking data outcomes to relevant concerns in health care as well as providing guidance for future research initiatives. In healthcare, the old hierarchy and paradigms are changing, fueled by multiple factors and pressures. Teamwork will need to be effective in both process and outcome as it becomes increasingly important. Experiences such as the one described here can be used as an impetus for team and research involvement.

Research also has to have "usability." This is best defined as "the extent to which a product can be used by specified users to achieve specified goals with effectiveness, efficiency and satisfaction in a specified context of use" ${ }^{[31]}$. In today's political and financial climate, usability is of utmost importance. As budget issues continue to hold center stage, the "fluff" research of the past may cease to exist/be funded and the demand for research that has clear-cut significance will hopefully continue to be funded. This process will demand and need an experienced, skilled leader as well as an effective team that is interdisciplinary, skilled, knowledgeable and effective. The authors are proud to have been part of this type of experience.

\section{References}

[1] Albert NM, Siedlicki SL. Developing and implementing a nursing research team in a clinical setting. Journal of Nursing Education. 2008; 38(2): 90-96.

[2] Chan R, Gardner G, Webster J, Geary A. Building research capacity in the nursing workforce: the design and evaluation of the nurse researcher. Australian Journal of Advanced Nursing. 2010; 27(4): 62-68.

[3] Fouladbakhsh JM. Complementary and alternative modalities to relieve osteoarthritis symptoms. A review of the evidence of several therapies often used for osteoarthritis management. Am J Nurs. 2012; 112(3): S44-S51. PMid:22373747 http://dx.doi.org/10.1097/01.NAJ.0000412651.10550.c1

[4] Fouladbakhsh JM, Stommel M. Comparative analysis of CAM use in the U.S. cancer and noncancer populations. J Complement Integr Med. 2008; 5(1 Art 19): 1-25.

[5] Fouladbakhsh JM, Stommel M. Gender, symptom experience, and use of complementary and alternative medicine among cancer survivors in the U.S. cancer population. Oncol Nurs Forum. 2010; 37(1): E7-E15. PMid:20044334 http://dx.doi.org/10.1188/10.ONF.E7-E15

[6] Gaguski ME, Brandsema M, Gernalin L, Martinez E. Assessing dyspnea in patients with non-small cell lung cancer in the acute care setting. Clin J Oncol Nurs. 2010; 14(4): 509-13. PMid:20682508 http://dx.doi.org/10.1188/10.CJON.509-513

[7] Molassiotis A, Zheng Y, Denton-Cardew L, Swindell R, Brunton L. Symptoms experienced by cancer patients during the first year from diagnosis: patient and informal caregiver ratings and agreement. Palliat Support Care. 2010; 8(3): 313-24. PMid:20875175 http://dx.doi.org/10.1017/S1478951510000118

[8] Podnos YD, Borneman TR, Koczywas M, Uman G, Ferrell BR. Symptom concerns and resource utilization in patients with lung cancer. J Palliat Med. 2007; 10(4): 899-903. PMid:17803411 http://dx.doi.org/10.1089/jpm.2006.0232

[9] Quast E, Williams M. Distress with breathing in people with lung cancer: a systematic review. The Internet Journal of Allied Health Sciences and Practice. 2009; 7(4): 1-11.

[10] Sarna L, Cooley ME, Brown JK, Chernecky C, Elashoff D, Kotlerman J. Symptom severity 1 to 4 months after thoracotomy for lung cancer. Am J Crit Care. 2008; 17(5): 455-67. PMid:18776002

[11] Sarna L, Evangelista L, Tashkin D, Padilla G, Holmes C, Brecht ML, Grannis F. Impact of respiratory symptoms and pulmonary function on quality of life of long-term survivors of non-small cell lung cancer. Chest. 2004; 125(2): 439-45. PMid:14769722 http://dx.doi.org/10.1378/chest.125.2.439

[12] Sarna L, Padilla G, Holmes C, Tashkin D, Brecht ML, Evangelista L. Quality of life of long-term survivors of non-small-cell lung cancer. J Clin Oncol. 2002; 20(13): 2920-9. PMid:12089220 http://dx.doi.org/10.1200/JCO.2002.09.045

[13] Thomas S, Bausewein C, Higginson I, Booth S. Breathlessness in cancer patients - implications, management and challenges. Eur J Oncol Nurs. 2011; 15(5): 459-69. PMid:21237709 http://dx.doi.org/10.1016/j.ejon.2010.11.013 
[14] Travers J, Dudgeon DJ, Amjadi K, McBride I, Dillon K, Laveneziana P, Ofir D, Webb KA, O’Donnell DE. Mechanisms of exertional dyspnea in patients with cancer. J Appl Physiol. 2008; 104(1): 57-66. PMid:17975124 http://dx.doi.org/10.1152/japplphysiol.00653.2007

[15] Büssing A, Ostermann T, Lüdtke R, Michalsen A. Effects of yoga interventions on pain and pain-associated disability: a meta-analysis. J Pain. 2012; 13(1): 1-9. PMid:22178433 http://dx.doi.org/10.1016/j.jpain.2011.10.001

[16] Campbell DE, Moore KA. Yoga as a preventative and treatment for depression, anxiety and stress. International Journal of Yoga Therapy. 2004; 14(1): 53-8.

[17] Donesky-Cuenco D, Nguyen HQ, Paul S, Carrieri-Kohlman V. Yoga therapy decreases dyspnea-related distress and improves functional performance in people with chronic obstructive pulmonary disease: a pilot study. J Altern Complement Med. 2009; 15(3): 225-34. PMid:19249998 http://dx.doi.org/10.1089/acm.2008.0389

[18] Fouladbakhsh JM, Davis JE, Yarandi H. Effects of a standardized yoga intervention on mood and salivary cortisol levels of stage I-IIIa non-small cell lung cancer patients. Proceedings of the 8th International Conference of the Society of Integrative Oncology, Cleveland, OH, Nov. 2011.

[19] Innes KE, Bourguignon C, Taylor AG. Risk indices associated with the insulin resistance syndrome, cardiovascular disease, and possible protection with yoga: a systematic review. J Am Board of Fam Pract. 2005; 18(6): 491-519. http://dx.doi.org/10.3122/jabfm.18.6.491

[20] Pullen PR, Nagamia SH, Mehta PJ, Thompson WR, Bernadot D, Hammond R, Parrott JM, Sola S, Khan BV. Effects of yoga on inflammation and exercise capacity in patients with chronic heart failure. J Cardiac Fail. 2008; 14(5): 407-13. PMid:18514933 http://dx.doi.org/10.1016/j.cardfail.2007.12.007

[21] Sherman KJ, Cherkin DC, Erro J, et al: Comparing yoga, exercise and a self-care book for chronic low back pain: a randomized controlled trial. Ann Intern Med. 2005; 143(12): 849-56. PMid:16365466

[22] Fouladbakhsh JM, Balneaves L. Assessment, Evaluation and Outcomes of CAM Use among Oncology Patients and Survivors. Presented at the 37th Oncology Nursing Society Congress, New Orleans, LA, May 4, 2012.

[23] Bliss J. Effective team management by district nurses. Br J Community Nurs. 2004; 9(12): 524-6. PMid:15655486

[24] Nelson LE, Morrison-Beedy DM. Research team training: moving beyond job descriptions. Appl Nurs Res. 2008; 21(3): 159-64. PMid:18684410 http://dx.doi.org/10.1016/j.apnr.2006.09.001

[25] O’Byrne L, Smith S. Models to enhance research capacity and capability in clinical nurses: a narrative review. J Clin Nurs. 2010; 20(9-10): 1365-71. PMid:21040029 http://dx.doi.org/10.1111/j.1365-2702.2010.03282.x

[26] Records K, Emerson RJ. Mentoring for research skill development. J Nurs Educ. 2003; 42(12): 553-7. PMid:14694996

[27] Fitzgerald M, Milberger P, Tomlinson PS, Peden-McAlpine C, Meiers MJ, Sherman S. Clinical nurse specialist participation on a collaborative research project: barriers and benefits. Clin Nurse Spec. 2003; 17(1): 44-9. PMid:12544120 http://dx.doi.org/10.1097/00002800-200301000-00020

[28] Albert NM, Siedlecki SL. Developing and implementing a nursing research team in a clinical setting. J Nurs Adm. 2008; 38(2): 90-6. PMid:18300841 http://dx.doi.org/10.1097/01.NNA.0000310714.30721.ca

[29] Vickers AJ. Basic introduction to research: how not to do research. J Soc Integr Oncol. 2008; 6(2): 82-5. PMid:18544288

[30] Cohen SG, Bailey DE. What makes teams work: group effectiveness research from the shop floor to the executive suite. Journal of Management. 1997; 23(3): 239-90. http://dx.doi.org/10.1177/014920639702300303

[31] Van Eijk D, van Kujik J, Hoolhurst F, Kim C, Harkema C, Dorrestijn S. Design for usability: practice-oriented research for user-centered product design. Work. 2012(1 Suppl); 1008-15. 